\title{
The long-stay psychiatric patient as consumer
}

\author{
I. C. T. Hughes, Principal Psychologist; B. M. McLackland, Research Assistant; \\ G. S. Oles, Research Assistant; I. G. PRYCE, Consultant Psychiatrist; and \\ R. D. P. Griffiths, Consultant Psychologist, Whitchurch Hospital, Park Road, \\ Whitchurch, Cardiff CF4 7XB
}

"Quality of life" (QOL) appears intrinsically important but difficult to measure. As a mental health professional, one might wish to know whether patients moving from the security of hospital to "the community" improve their QOL, or to evaluate their QOL against that of other groups in society. Simply looking at symptom change or economic cost-benefit misses much of the point behind innovations in psychiatric services. From previous QOL assessments (e.g. Lehman, 1983) one would focus upon positive aspects such as living situation, personal relationships, and general health and on negative aspects such as lack of money or being a victim of crime. Literature from the 1950 s and 60 s attests to the adverse effects of institutional care but more recently writers such as Kathleen Jones (Jones et al, 1986) have drawn attention to the benefits of living in such an environment. Also, various well-publicised "scandals" have suggested the pitfalls of inadequately thought-out discharge into the community.

Another useful strand to consider when attempting to assess QOL is to learn from the "normalisation" literature as applied to people with learning disabilities. This implies that one way of defining "quality" is in terms of what is generally socially valued. Hence, some comparison with nonstigmatised groups is a pre-requisite.

As well as attempting "objectively" to assess QOL for patients currently resident in South Glamorgan psychiatric facilities, our study involved asking patients about their personal preferences. A similar study, carried out at Goodmayes Hospital (Abrahamson et al, 1989), found that $56 \%$ of the long-stay population were able to participate in the interview process. Of these, the majority expressed some desire to leave hospital, and this trend was more apparent in those who were aware of alternatives outside. More recently, Dayson (1990) confirmed that there tends to be a shift towards a more favourable view towards community residents the longer people have been living outside hospital.

\section{The study}

A sample of 70 patients ( 22 men, 48 women), randomly selected from our long-stay population (156 in total) was defined by in-patient status for over a year and absence of dementia. The mean age is 63 years, most patients having been resident in hospital for a considerable time (mean $=17.7$ years). All 70 patients were invited to participate in our survey: 48 agreed, 10 refused and 12 were unable to take part because of ill health, infirmity or inability to speak English. There were 15 men and 33 women aged 29 to 86 years, mean 61.8 years.

\section{Assessing QOL}

To attempt an "objective" assessment of the patients' QOL, their primary nurse was interviewed and asked about material aspects of the patients' environment, their freedom of choice, privacy, personal belongings, recent involvement in local community activities and about any negative occurrences. (The questionnaire and full results may be obtained from the first author.)

A comparison group of middle-aged and elderly attenders at a local chapel luncheon club was also assessed: 30 community residents, with a mean age of 66.8 years, and women outnumbering men 19:11. These people lived near the psychiatric hospital, so, in theory, had access to similar facilities as the in-patient sample. This comparison group is not a matched control group, although mostly of the same generation and cultural background. Members of this community sample were given an interview similar to that used with the in-patients (by GO).

To assess in-patient preferences, the 48 patients were interviewed (by BMcL) to check the orientation of the patients involved. About two-thirds of the sample understood all the questions and gave answers which can be relied upon. From the original, randomly-chosen sample of 70 patients, 32 (i.e. 46\%) were willing and able to provide meaningful opinions about their life in hospital, similar to the figure of $50 \%$ in the Goodmayes study.

\section{Findings}

The community residents were significantly (at the $5 \%$ level) more likely to have the following QOL aspects: an outdoor area for relaxation; access to a telephone; a quiet room in which to relax; a daily 
newspaper; electric kettle and cooker. Surprisingly, patients were significantly more likely to have access to a video recorder.

Virtually all the in-patients claimed to be able to choose when they retired at night, although only $4 \%$ were said to have flexibility concerning when they ate their main meals. Only $29 \%$ of patients either had a private bedroom or shared with one other person of their choice, $43 \%$ a secure, personal locker in which to store personal property, $30 \%$ personal leisure items and $4 \%$ any other major furnishing in their bedroom/bed space. In these regards, our in-patient population is severely disadvantaged with respect to the community residents. Furthermore, the patients were much less likely over the previous two weeks to have been: shopping outside hospital, involved in any local social activity, on public transport, to visit family, to visit a friend, involved in any individual hobby, to a public entertainment such as a cinema or concert, to use savings facilities such as a bank or building society, to attend a religious service or equivalent meeting, engaged in voluntary work, reading a book or visiting a local library. None of the activities had been engaged in by more than half the patients.

Fifty-six per cent of the patients and $97 \%$ of the community sample said that they were "satisfied or happy" with where they lived, while $27 \%$ of the patients and none of the community residents described themselves as "dissatisfied or unhappy", a highly significant difference. Residents focused upon features such as "good facilities", plenty of open spaces and good bus services as desirable features of their neighbourhood, while patients selected nurses, food and general comfort of the hospital as making for good quality of life. Most patients were unable to describe any particular thing which they disliked about hospital, while community residents complained about litter, traffic and poor condition of the pavements. When asked whether they would wish to remain in their present circumstances, $93 \%$ of the community residents answered "yes", but only $52 \%$ of the patients did so.

Of those patients wishing to leave hospital, almost half wished to return to their "own home", which was unrealistic in most cases. Most wished to live with other people, rather than on their own. Usually this meant with relatives or friends-again it is not clear how realistic this was.

\section{Comment}

Our study found that long-stay psychiatric patients had a lower QOL than a comparison group who lived in the same part of Cardiff. In particular, our patients engaged in very few community activities. This was probably not because of age and infirmity (which were as great in the luncheon club attenders), nor distance from facilities. Facilities were there, and could have been used - but were not.

When an attempt was made to obtain a "consumer's view", less than half those invited were able to participate in a meaningful way. Hence questions arise as to how far our findings can be generalised. Even those patients who did participate often provided vague answers.

When attempting to make a broad assessment of QOL, there is a tendency to rely more on "hard" than "soft" objective data obtained from the person involved. This may be ethically dubious but seems inevitable in light of the limited cognitive competence and co-operation of many of those involved. Our study allows us to assert that patients engage in fewer activities which are culturally valued than do people in the community comparison groups, but it does not allow us to state that the QOL of the community group is so many times better than that of the patients.

Also, when assessing a person's QOL, one should be wary of assuming that "health norms" are always appropriate. The severely handicapped chronic schizophrenic person, even when living outside hospital, may choose to lead a life which most people would regard as socially impoverished: this may be done because the sufferer knows that otherwise he/ she would exacerbate the positive symptoms of what remains a distressing, illness. "Freedom to choose" may, paradoxically, lead to what appears to be a lower quality of life.

\section{References}

Abrahamson, D., Swatton, J. \& Wills, W. (1989) Do long-stay psychiatric patients want to leave hospital? Health Trends, 21, 17-19.

DAYSON, D. (1990) Clinical and social outcomes after one year in the community. Paper presented at TAPS fifth annual conference.

Jones, K., Robinson, M. \& Golightly, M. (1986) Longterm psychiatric patients in the community. British Journal of Psychiatry, 149, 537-540.

LeHMAN, A. S. (1983) The well-being of chronic mental patients: assessing their quality of life. Archives of General Psychiatry, 40, 369-373. 